\title{
Perception of Sexual Harassment in Nigeria's Universities
}

\author{
S. S. Ifah, Mrs. O.O. Badejo \& Mrs. R.O.Folorunso \\ University of Maiduguri, Maiduguri, Nigeria.
}

\section{Introduction}

The term sexual harassment first appeared in the United States and the United Kingdom in the early 1970s and 1980s respectively, following protests by women's groups about their treatment in the workplace. Rubenstein (1987) defines sexual harassment as, "any verbal or physical conduct of a sexual nature which the perpetrator knows or should have realised was offensive to the victim". Such unsolicited or nonreciprocal male behaviour usually assert a woman's sex role over her functions as a student or worker (Farley 1978). A fairly comprehensive definition of sexual harassment is that of the Britain's Trade Union Congress (1983) which regards sexual harassment as sexual advance or sexually explicit derogatory statements or sexually discriminating remarks, made by someone in the work force which are offensive to the workers involved; which cause the workers to feel threatened, humiliated, patronised or harassed; or which interfere with the worker's job performance, undermine job security or create a threatening or intimidating work environment.

The United States' National Advisory Council on Women's Educational Programmes maintains, "academic sexual harassment is the use of authority to emphasise the sexuality or sexual identity of a student in a manner which prevents or impairs that student's full enjoyment of educational benefits, climate or opportunities" (Till 1980).

The university of Washington official definition of sexual harassment includes any unwelcome sexual advances, requests for sexual favours or other verbal or physical conduct of a sexual nature carried out by someone at the work place or educational 
setting. Such behaviours usually offend the recipient, cause discomfort, humiliate and interfere with job or school performance. Coles (1986) while pointing out that a single definition of sexual harassment was fraught with difficulty, draws a distinction between sexual harassment in terms of sexual compliance exchanged or proposed to be exchanged, for some favours (e.g good examination grades, employment, etc.) and harassment as part of normal working life. The former usually involves outright sexual demand (and is more easily recognised as sexual harass-ment), while the latter involves making a woman's learning or > working environment unpleasant, is seen as "normal" male behaviour and therefore, creates and perpetuates an atmosphere of sex discrimination.

Sexual harassment can therefore be operationally defined as unwelcome and uninvited sexual advances (in physical or verbal forms). Specific forms of sexual harassment behaviour "include insensitive jokes or pranks, displays of pornographic pictures, lewd comments about physical appearance, requests for sexual favours, questioning or bantering about aspects of a woman's private life and explicit sexual violence" (Kremer and Marks 1990).

\section{Models of Sexual Harassment}

Tangri, Burt and Johnson (1982) identified three models of sexual harassment: the natural or biological model, the organisational model, and the socio-cultural model. According to them the natural/biological model, a motivational model, assumes that sexual harassment is a natural sexual attraction between two people. Sexual harassment by men is simply a harmless expression of their stronger sexual drives that is without any discriminatory or harassing intent. Harmful sexual harassment behaviour should be blamed on the "idiosyncratic" behaviour of a minority of men. Tangri et al point out that this model, which seems to trivialize and so aggravate sexual harassment, has been most vehemently used in court by corporations seeking to avoid charges of sex discrimination or sexual harassment. The biological model is the primary interpretation in need of change in an effort to bring it under the sex discrimination laws. 
The organisational model stresses facilitating forces and assumes that sexual harassment is due to "certain opportunity structures created by organisational climate, hierarchy, and specific authority relations", (Tangri et al. 1982). Sexual harassment behaviour is due to vertical stratification in which those in authority can use their subordinates. Both sexes can therefore be guilty of sexual harassment but there are more women victims because employed women often tend to be subordinate to men, possess the least organisational power and face the greatest economic disadvantage. According to Tangri et al "it is the work place infrastructure that provides opportunities for sexual aggression".

The socio-cultural model sees sexual harassment as "one manifestation of the large patriarchal system in which men rule and social belief legitimise their rule. Male dominance is maintained by cultural patterns of male-female interaction as well as by economic and political superordinancy. Society rewards males for aggressive and domineering sexual behaviours and females for passivity and acquiesce. Members of each sex are encouraged to play their respective and complementary roles. Because women, more than men, are taught to see their self-worth in the evaluation of others, particularly of men, they are predisposed to try and interpret male attention as flattery, making them less likely to define unwanted attention as harassment. They are trained to be sexually attractive, to be social facilitators and avoid conflicts and not to trust their vulnerability to sexual harassment" (Tangri et al. 1982). Sexual harassment can therefore be viewed as an assertion of power and not as motivated by sexual desire or an attempt to form a reciprocal romantic relationship.

This research is guided by this quotation on the socio-cultural: explanation of sexual harassment. Research has consistently shown that in Europe and America with a relatively high level of women emancipation awareness, sexual harassment is widespread (Rubenstein 1987; Farley 1878; Kremer and Curry 1986). 
Other studies on sexual harrassment in universities include the following: Till (1981), Wilson and Krans (1981), Lott and Reilly (1980), Benson and Thomson (1982), Irvine and Somers (1982), Glaser and Thorpe (1986) and Singer (1989) to name the key ones.

These studies indicate that sexual harassment is a fairly common problem in most university campuses in the U.S and presumably in Europe. The incidents are bound to be higher in Nigeria than in Europe and America for several reasons, the most important of which is the centuries-old discrimination, oppression and exploitation of women by men and the acceptance by both that the former's primary place and role are in the kitchen and rearing respectively. Yet the women's contributions - reproductive and productive - to social, cultural and economic development has never been in doubt.

Even in the developed countries, sexual harassment has not only been underreported, its understanding as a social problem is trivialized by those not directly negatively affected, especially men. An important reason for this lukewarm attitude to the subject has been offered by Kremer and Marks (1990): the labelling of incident as normal or everyday inevitably makes any complaint (and by inference the complainant) appear to be abnormal to fellow employees, management and even friends and relatives, irrespective of the seriousness of the incident(s) or the personal distress experienced by the victim. The reticence of so many individuals to bring complaints is therefore very understandable given these attitudes and given their future prospects at work, having publicly declared that this type of behaviour is unacceptable to them.

Significant sex differences on what constitutes sexual harassment behaviour have been reported in the literature (Gutek et al. 1980; Benson and Thomson 1982; Jenson and Gutek 1982). For example Jenson and Gutek (1982) report that men and women differ in their assignment of responsibility regarding sexual harassment at the work place. "Men are more likely than women to 
blame women for being sexually harassed. Among women, victims are less likely than others to blame women for being sexually harassed" (Jenson and Gutek 1982). They also found that sex role belief would determine how a woman who has been sexually harassed feels about the incident. According to them "if she will be highly likely to blame other women, as well as herself for incidents of sexual harassment. Such an attribution process in turn, will affect whether she reports the incident to someone in authority or talks to "co-workers or friends about it" (Jenson and Gutek 1982).

Even for the emancipated woman, the personal social-psychological costs of pursuing a claim are often too much for being sexually harassed. For example, interpersonal relationships must inevitably suffer. Apart from the trauma associated with bringing a complaint, an intimate, certainly embarrassing questioning will follow. Victims suffer psychologically and economically as a result of sexual harassment experiences (Farley 1978; Safran 1976; U.S Merit Systems Protection Board 1981). Livingstone (1982) points out that the individual, institutional, and socio-economic consequences of sexual harassment have helped to establish it as a legitimate social problem. For example, it has been reported that the U.S federal government incurs an estimated loss of \$189 million in a two-year period (due to turnover and medical bills resulting from sexual harassment of its employees (U.S Merit Systems Protection Board 1981).

To many feminists, sexual harassment is a way of perpetuating women's highly unfavourable social and economic status. Tangri'et al. (1982) in their enunciation of the socio-cultural explanation of sexual harassment point that it is used to manage ongoing male-female interaction according to accepted sex status norms and to maintain male dominance occupationally and therefore economically by intimidating, discouraging, or precipitating removal of women from work.

Some specific personal effects of sexual harassment could be psychological (anger, fear, depression, anxiety, confusion, 
irritability, feelings of humiliation, loss of self-esteem, helplessness, alienation and vulnerability); physical (loss of appetite and weight, headaches); occupational (decreased morale, increased absenteeism and lack of concentration).

In Britain, serious incidents of sexual harassment are prosecuted under the Sex Discrimination Act (1975) once the complainant shows that harassment has caused disadvantage of some kind and that the harassment was sexual in nature. In the United States, laws dealing with sexual harassment are based on Title VII of the Civil Rights Act of 1964, which forbids discrimination in employment on the basis of sex, race, religion, or national origin. The Equal Employment Opportunity Commission was created by this act. The commission issued rules in the 1980s stating that an employer must provide a work environment free from sexual harassment or intimidation. This rule was upheld in 1986 when The U.S. Supreme Court ruled in Meritor Saving Bank vs. Vinson that sexual harassment creates a hostile or abusive work environment, even when the victim does not suffer economic loss. In these countries, employees who have been subjected to sexual harassment can file suits in civil courts against employers and ask for monetary damages from them. The recent most celebrated example is the suit brought against the American President, Bill Clinton, by Paula Jones, a female employee, when he was the Governor of the State of Arkansas. The President paid huge sums of money in an out of court settlement arranged by the parties' lawyers.

In Nigeria, the National Council on Education, the nation's highest policy making body on education, had, in February 1984, recommended that a National Committee on Sexual Harassment should identify the causes and types/practices of sexual harassment and indecent assault in educational institutions, the problems of co-educational schools, and the desirability and possibility of free and compulsory education for girls up to the age of 18 . The committee used the questionnaire as the main method of data gathering. 
Nearly half of the respondents did not agree that (1) students of the rich and famous families were mainly responsible for sexual harassment, (2) female students, sexually harassed their male colleagues, (3) male students sexually harassed fellow female students, and (4) students who knew the secrets of other students resort to sexual harassment for them to keep the secrets.

Most of the respondents believed that (1) students may lure fellow students into circumstances which result in sexual harassment, (2) female students are the ones who sexually harassed male students, (3) female students are helpless in the hands of persistent male lecturers, (4) male lecturers intimidate female students with loss of grades, (5) male lecturers recruit female students for visitors, and (6) male lecturers sexually harassed female students because others are doing it. Two-thirds of the respondents believed that female students who have been sexually harassed may suffer psychological setbacks and that they may get used to it and regard sexual harassment as normal. About $72 \%$ felt that female students who yielded to sexual harassment were not likely to be faithful to their husbands.

The committee recommended the restructuring of education laws to include ethical provisions with specific penalties for sexual harassment in Nigeria's educational institutions, investigation of cases of sexual harassment and making appropriate recommendations, and that legal provisions on sexual harassment be incorporated in the penal code.

The committee's study was a bold attempt at examining the problem of sexual harassment in educational institutions in Nigeria. However, the committee failed to examine the subjects' perceptions and prioritizations of acts of sexual harassment.

Sexual harassment has been the most controversial topic of discussion in Nigeria's universities. Teachers are often accused of inflating the examination marks of their girlfriends while failing female students who snub their sexual advances. This view is widely held both within and outside the university campuses. 
Public opinion of student-lecturer relations has been prejudiced by this phenomenon. Yet, few, if any, government establishments, companies, universities and other educational institutions, have formal sexual harassment policies setting out what constitutes the offence, that it will not be tolerated and that allegations will be treated swiftly, seriously, and confidentially. This is unlike most developed countries where most businesses have sexual harassment policies.

In Nigeria, although section 42 of the 1999 constitution forbids discrimination on grounds of race or ethnicity, religion, politics, class, sex, age, or a combination of such factors. There are no specific laws dealing with sexual harassment.

The objective of the study was to examine the public perception and incidence of sexual harassment in Nigeria's universities.

\section{Methodology}

The respondents were selected from eight academic departments in four faculties at the following universities: University of Nigeria, Nsukka; University of Calabar; University of Jos; Ahmadu Bello University; University of Maiduguri; University of Ibadan; University of Lagos and University of Benin. A semi-structured questionnaire was designed and distributed among students and staff members in each of the academic departments as follows: 13 female students in the penultimate and final years; 10 male students in the penultimate and final years; 3 lecturers; 2 post graduate students, bringing the total of respondents to 1792 respondents in all the selected departments/universities. The questionnaire was designed to gather data on the demographic attributes of respondents including their perception toward, sexual harassment. 


\section{Perception of Sexual Harassment}

Less than half of the respondents in the four sub-samples regarded suggestive remarks/verbal abuse and offensive pin-ups and calendars as acts of sexual harassment. A higher percentage of the female staff sub-sample did not consider these acts as sexual harassment behaviour. The reverse was the case for sexist or patronising acts which about $50 \%$ of the male and female students' sub-samples but only a third of the female staff regarded as acts of sexual harassment.

Half of the female students' sub-sample and about a third of male's regarded leering and eying as acts of sexual harassment. Sexual propositions and compromising invitations were considered by about a half and a third respectively, of all the four subsamples, as sexual harassment. Over $60 \%$ of the respondents considered demand for sexual favours as sexual harassment. Similar results were obtained for unnecessary touching/unwanted contact, except among female staff where only $48 \%$ considered it as sexual harassment. Surprisingly, $44 \%$ of the same sample considered unnecessary touching as not constituting sexual harassment. A third and above of all the four subsamples felt that physical assault and rape constitute sexual harassment.

About $45 \%$ of the students' sub-sample, a half of the male staff, but only a third of the female staff, considered suggestive remarks and other verbal abuse as serious social problem. $40 \%$ of each of the four sub-samples considered offensive pin-ups and calendars as serious social problem. Over a half of the male and female samples regarded sexist or patronising acts as serious social problems whereas only $38 \%$ of the female staff regarded it as such. $46 \%$ of the female sub-sample and $36 \%$ of the male felt that leering or eyeing a person's body are serious social problems. The same result was obtained for compromising invitations, which a higher percentage of the female staff considered as a serious social problem. Sexual proposition was viewed by over half of the staff samples and about $43 \%$ of the students' sample as a serious social 
problem while over $60 \%$ of each of the four sub-samples regarded the demand for sexual favours as a serious social problem. About the same percentage in all the subsamples except among female staff, considered unnecessary touching/unwanted contact as serious social problems. Only $48 \%$ of the female staff sub-sample regarded this act as a serious social problem in contrast to more than two-thirds of the respondents in each of the four sub-samples who regarded physical assault and rape serious social problems.

One of the main objectives of the study was to ascertain from the standpoint of the respondents how widespread is the incidence of sexual harassment in Nigeria's universities. The results indicate that about a quarter and a third of the male students and staff respectively, and $45 \%$ and $67 \%$ of their corresponding female counterparts claimed they had been sexually harassed. This reveals that more female staff than female students were sexually harassed. About half of the male sub-sample reported being sexually harassed by students and about the same percentage of the female sub-sample claimed that they had been harassed by lecturers. These results indicate that more male respondents said they were sexually harassed by students and that significantly more female respondents said they had been sexually harassed by lecturers.

The University of Lagos had the highest percentage (74.5\%) of female victims followed by University of Benin (61.4\%) and University of Nigeria, Nsukka (45.5\%). Over $66 \%$ of the female sub-sample reported knowing someone who had been sexually harassed compared to about half in the male sub-sample. More female respondents said they knew of someone sexually harassed by lecturers. Moreover, about $80 \%$ of each of the four sub-samples agreed that girls were the victims of known cases of sexual harassment.

Close to $40 \%$ of the students' sub-sample, $52 \%$ in the male staff sub-sample, and a third among the female staff respondents I said they always hear of incidents of sexual harassment as opposed 
to a third in each sample that rarely heard of it. The results suggest that less than $10 \%$ of the male and female student's sub-samples and about $12 \%$ of the female staff claimed that they had always been sexually harassed. Majority of the respondents but only a third of the latter sample said they had never been sexually harassed.

$49 \%$ and $47 \%$ of the male students and staff respectively, had been victims of sexual harassment and felt insulted and angry about the incident. The corresponding figures for the female samples were much higher (69\% and $85 \%)$ suggesting that more female victims were angry and assaulted.

The results also suggest that over a half of the female students but only a third of each of the other three sub-samples, felt definitely threatened by their sexual harassment experiences. A higher percentage of the female sub-samples claimed that they were not excited or glad when they were sexually harassed.

Although a majority of the victims blamed their harassers, this was done by a significantly higher percentage of the female samples. Furthermore, about a quarter of the students but a third of the staff samples blamed themselves for their sexual harassment experiences. The results show that only $28 \%$ of the male sub-samples, compared to $45 \%$ and $65 \%$ of the female students and staff respectively did not blame themselves and their harassers. About a third of the male and female students' sub-samples blamed society but $71 \%$ of the female staff felt that it definitely was not to blame.

As regards reporting cases of sexual harassment, most victims do not report, when sexually harassed. $80 \%$ and more of the victims in each of the four samples said that they did not report the incidents. The main reason for not reporting is because people will laugh at them and that nothing would be done about it. Over half of the female sub-sample was emphatic about the former reason while more male respondents were definite about the latter reason. 


\section{Discussion}

The results of this study do not indicate any significant gender differences in the perceptions of behaviours people consider as sexual harassment in Nigeria's universities elsewhere in the study by Gutek et al. (1980), Benson and Thomson (1982), Jenson and Gutek (1982). On the other hand, the results seem to suggest that a lesser percentage of the female staff considered unnecessary touching/unwanted contact as sexual harassment than the female samples. This may be due to what Farley (1978) referred to as the "casting couch" myth that women respond positively to male sexual advances. Farley argues that in a patriarchal system "men make the rules to which females are expected either to conform or get out". The system encourages women to play their assigned roles of being sexually subservient while the males are expected to be dominant. The roles are carried out so well that females may, like their male counterparts, not consider certain behaviours as sexual harassment.

Similar results were obtained on whether or not certain behaviours were serious social problems. The behaviours con-sidered as problems were demand for sexual favours, unnecessary touching/unwanted contact and physical assault and rape. The others were regarded as normal every day occurrences.

The main significant differences between the male and female samples were as regards the number of victims of sexual harassment. As expected, the females were significantly more harassed than the male. The percentages of those harassed were extremely high when compared to research evidence from other places. The results revealed that sexual harassment was significantly higher among female staff than female students. This may be due to the longer exposure to sexually harassing experiences of the former than the latter (through the world of learning to the world of work). As expected, a significantly higher percentage of respondents reported knowing of other people being sexually harassed than being harassed themselves. This is consis- 
tent with the findings that respondents may be more willing to discuss other people's experiences than their own (Lott and Reily 1980). As expected, most of these other victims were females, sexually harassed by lecturers.

The results are also consistent with previous findings that most victims do not report their experiences. Indeed, as part of the methods of study, it was our intention to conduct in-depth interviews with some victims. This was dropped when nobody was willing to openly admit to being sexually harassed. The reasons for not reporting were that people would laugh at them and that there were no avenues for reporting it. Most of the victims blamed the harassers but it is noteworthy that over a third of the female staff blamed themselves for their sexual harassment experiences.

We believe that the problem of sexual harassment is a deep-rooted gender issue in a patriarchal system like ours, organised according to a principle of male rule, where sexual harassment has been a completely acceptable idea (Farley 1978). The results of this study strongly suggest that sexual harassment is prevalent in Nigeria's universities.

\section{Policy Recommendations}

We agree with most of the recommendations of the National Committee on Sexual Harassment. In addition and specifically we recommend the following:

1. High powered senate investigation and disciplinary committees on sexual harassment should be set up in all the universities and other higher institutions in Nigeria. Victims of sexual harassment should be encouraged to make confidential complaints. Students should be informed of their rights and avenues for complaints and redress. For as has been suggested any policy seeking to inhibit sexual harassment must find ways of making it "safe" for victims of sexual harassment to reveal information at no cost to themselves. If a policy is to have any meaning it should ensure that no one reporting harassment would be disadvant- 
aged in any way by her revelation (Garett and Thomas, 1992).

2. Offenders should be punished in the form of an apology, suspension or dismissal, while the victims should be compensated.

3. The system of internal and external moderation of examination questions and answers should be strengthened. Teachers consistently accused or suspected to be 1 perpetrators of sexual harassment should have their examination results closely monitored by either or both the internal and external moderators.

4. Within the university communities as elsewhere either sex could theoretically be a victim of sexual harassment but we recommend that more female teachers should be employed since the female students are often the major targets. This is a similar to a solution to sexual harassment in the work place suggested by Farley (1978). The obvious solution is a totally integrated work force with both sexes sharing equally in all jobs and all authority throughout the hierarchies of business power. This kind of change, however, will require nothing less than an alteration in the balance of power at work. This will bring about some balance in gender power relations in the universities.

5. Female students and staff should organise themselves to stop sexual harassment in universities and other higher institutions in Nigeria. For, as in the work place according to Farley (1978), sexual harassment will be stopped when women finally take control of their own labour power via collective bargaining and striking to regain their rights. This will be a long fight, but it is the inevitable future. The sexual harassment of women at work is an intolerable working condition that negatively affects everyone. It is as onerous to the women as rape, and as important as abortion because it involves the right to control their own bodies. 
6. Future research on sexual harassment in Nigeria should be conducted in the work place - both public and private. Such a study should employ both quantitative and qualitative methods and should avoid the flaws of this study.

\section{References}

Benson, D. and Thomson, G. (1982) "Sexual Harassment on a University Campus: The Confluence of Authority Relations, Sexual interest and Gender Stratification", Social Problems, 24,236-251.

Bogart, K. and Stein, N. (1987) "Breaking the Silence: Sexual Harassment in Education", Peabody Journal of Education, 64,4: 146-163.

Coles, F. S. (1986) "Forced to quit: Sexual Harassment Complaints and Agency Response", Sex Roles, 14, 1: 81-95.

Farley, L (1978) Sexual Shakedown: The Sexual Harassment of Women in the Working World, London: Melbourne House.

Garrett, T. and Thomas, P. (1992) "Sexual Harassment”, The Psychologist, 5,7:319-321

Glaser, R. D. and Thorpe J, S. (1986) "Unethical Intimacy: A Survey of Sexual Contact and Advances between Psychology, Education and Female Graduate Students", American Psychologist, 41, 1: 43-51.

Gutek, B. A., Nakamura, C. Y., Gahart, M. Handschucher, I. and Russell, D. (1980) "Sexuality and the Workplace", Basic and Applied Social Psychology, 1: 255256.

Jensen, I. W. and Gutek, B. A. (1982) "Attributions and Assignments of Responsibility in Sexual Harassment", Journal of Social Issues, 38: 121-136.

Kremer, J. and Curry, C. (1986) Attitudes Towards Women in Nor-thern Ireland, Belfast: Equal Opportunities Commission For Northern Ireland. 
Perception of Sexual Harassment in Nigeria's Universities 59

Kremer, J. and Marks, J. (1990) Sexual Harassment at Work in . Northern Ireland, Belfast: Equal Opportunities Commission For Northern Ireland.

Livingstone, J. (1982) "Responses to Sexual Harassment on the Job: Legal, Organisational and Individual Actions", Journal of Social Issues, 38: 5-22.

Lott, B. R. and Reilly, M. E. (1980) Assessment of Sexual Harassment within the University of Rhode Island. Providence: Assessment Test Group.

National Committee on Sexual Harassment (1989) Sexual Harass-ment in Educational Institutions in Nigeria. Committee's Report. Lagos: Federal Ministry of Education.

Rubenstein, M. (1987) The Dignity of Women at Work: A Report on the Problems of Sexual Harassment in the Member-States of the European Community. Brussels: Commission of the European Communities.

Safran, C. (1976) "What Men do to Women on the Job: A Shock-ing Look at Sexual Harassment", Red Book, 149: 217-224.

Somers, A. (1982) "Sexual Harassment in Academe: Legal Issues and Definitions", Journal of Social Issues, 38, 4: 23-32.

Tangri, S. S., Hurt, M. M. and Johnson, L. B. (1982) "Sexual Harassment at Work: Three Explanatory Models", Journal of Social Issues, 38, 4: 33-34.

Till, F. (1980) Sexual Harassment: A report on the Sexual Harassment of Students, Washington DC: U.S. Department of Education.

Trades Union Congress (1983) Sexual Harassment at Work: Guidelines. London: TUC House.

Wilson, K. and Kraus, L. (1981) "Sexual Harassment in the University", Journal of College Students Personnel, 24: 219-224. 